\title{
Molecular Characterization of Seven Different Species of Aspergillus through Random Amplified Polymorphic DNA (RAPD) and Enzyme Analysis
}

\author{
Saba Irshad*, Rabiya Nawab \\ Institute of Biochemistry and Biotechnology University of the Punjab Lahore, 54590, Pakistan \\ saba.ibb@pu.edu.pk, sabairshad2003@yahoo.com
}

\begin{abstract}
The aim of this study was to characterize seven species of Aspergillus at molecular level, using random amplification of polymorphic DNA (RAPD). RAPD- PCR conditions were optimized for two primers of series B, GL Decamer B-09 and GL Decamer B-10 out of 10 total primers. RAPD results were evaluated by a statistical software Minitab and a phylogenetic tree was prepared. GL Decamer B-09 showed 38 bands and GL Decamer B-10 gave 46 bands, showing 50\% and $57 \%$ similarity respectively, among species. Biochemical characterization was done by screening of zones production with particular enzyme activity of each specie resulted in particular substrate degradation.
\end{abstract}

Keywords Aspergillus, RAPD, Minitab, Pectinase activity, Phylogeny

\section{Introduction}

There are an estimated 1.5 million fungal species of which around 70,000 have been described so far[1]. Aspergillus is a filamentous and ubiquitous fungus found in nature and is identified at species level by using the differential culture media. A total of 205 Aspergillus species are reported which includes $153(75 \%)$ environmental and $52(25 \%)$ clinical Aspergilli[2].

Aspergillus niger is economically important fermentation organism used for the production of citric acid and it represents highest yield bioprocess, currently in use by industry[3]. Aspergillus fumigatus is considered to be the most frequent isolate from clinically immunocompromised patients, but other important species include $A$. flavus, $A$. niger and A. terreus as a cause of opportunistic infections[4]. Phenotypic and genotypic correlations provide strong evidence for differentiation of $A$. flavus from A. oryzae, though there are very minor phenotypic and genotypic differences[5]. Bacterial strains are effective in reducing soil populations of mycotoxigenic fungi; thereby reduce fungal spore formation and crop plant infection via airborne transmission[6].

PCR-based technique, involving the random amplification of polymorphic DNA (RAPD) has been used for assessing genomic variability among a wide range of culture collection

* Corresponding author:

saba.ibb@pu.edu.pk (Saba Irshad)

Published online at http://journal.sapub.org/microbiology

Copyright (C) 2012 Scientific \& Academic Publishing. All Rights Reserved strains of Aspergillus and related species[7]. The utility of DNA markers as RAPD-DNA employ it as well established sample molecular marker tool for detecting genetic variability for many phytopathogenic fungi[8].

DNA Polymorphisms based on differences in DNA sequences, have advantages over protein polymorphisms[9]. The application of the random amplification of polymorphic DNA (RAPD) assay to the human pathogen A. fumigatus was described in the year 1993[10]. RAPD fingerprinting is used to gain rapid and precise information about genetic similarities and dissimilarities of different Aspergillus species. RAPD fingerprints of A. niger, A. flavus and A. parasiticus revealed polymorphism in $37,59,51 \%$ of the analyzed Aspergillus species[11].

RAPD polymorphism results from a nucleotide base change, an insertion or deletion that alters the primer binding sites. This product can be polymorphic and may be used as genetic markers for extensive genetic variation analysis[12]. One advantage of this technique is that the primers are universal and they can be used for genomic analysis of a wide variety of species[13].

The research project of analyzing genetic diversity by RAPD PCR is very useful to detect similarities and differences in different fungal species. Random Amplified Polymorphic DNA, more or less randomly distributed in the whole genome[14]. They span the majority of the chromosome and map both proximal and distal to the centromeres and are also able to map novel chromosomal regions. In the present study we have characterized seven different Aspergillus strains i.e A. niger, A. nidulans, A. parasiticus, A. flavus, A. japonicus, A. oryzae and A. fumigatus. The aim of 
the present study was to characterize seven different species of fungi at molecular level that leads to further elucidation of genetic diversity.

\section{Material and Methods}

\subsection{Source of Fungi}

The fungal samples were obtained from First Fungal Culture Bank of University of the Punjab Lahore at Department of Mycology and Plant Pathology (MPPL) and maintained in test tubes as slants and stored at $4^{\circ} \mathrm{C}$. Seven different species of Aspergillus with their accession numbers, A. japonicus (503), A. niger (706), A. parasiticus (174), A. nidulans (722), A. flavus (647), A. oryzae (01) and $A$. fumigatus $(651)$ were grown at $24-25^{\circ} \mathrm{C}$.

\subsection{Preparation of Culture}

Slants prepared in test tubes containing $5 \mathrm{ml}$ of autoclaved medium (1 g yeast, $1 \mathrm{~g}$ peptone, $1 \mathrm{~g}$ starch and $1 \mathrm{~g}$ agar in 100 $\mathrm{ml}$ water) were inoculated with their respective cultures with the help of loop and incubated at $37^{\circ} \mathrm{C}$ for $3-4$ days. When growth appeared, they were stored at $-20^{\circ} \mathrm{C}$. A single colony from the starter culture was inoculated in $30 \mathrm{ml}$ of autoclaved broth $\left(0.01 \mathrm{~g} \mathrm{Fe} \mathrm{SO}_{4}, 0.50 \mathrm{~g} \mathrm{KCl}, 0.50 \mathrm{~g} \mathrm{Mg} \mathrm{SO}_{4}, 1 \mathrm{~g}\right.$ $\mathrm{K}_{2} \mathrm{HPO}_{4}, 3 \mathrm{~g} \mathrm{NaNO}_{3}$ and $20 \mathrm{~g}$ sucrose in one liter of water) in a $100 \mathrm{ml}$ conical flask. Flask was covered with cotton plug and aluminum foil and placed in incubator for 4 days at $27^{\circ} \mathrm{C}$. Growth appeared after one week.

\subsection{RAPD PCR Amplifications}

Total DNA of fungal samples were extracted manually by CTAB method[15]. Optimized primer GL DecamerB-09: 5 TGGGGGACTC 3' and Primer GL DecamerB-10: 5` CTGCTGGGAC 3` were used for PCR of isolated DNA. 50 $\mu 1$ reaction mixture, containing $10 \mathrm{X}$ PCR buffer $(5 \mu \mathrm{l}), 5 \mathrm{mM}$ dNTPs mix $(2 \mu \mathrm{l}), 5 \mathrm{U} / \mu \mathrm{l}$ Taq DNA polymerase $(0.6 \mu \mathrm{l})$, template DNA $(5 \mu \mathrm{l}), 25 \mathrm{mM} \mathrm{MgCl}_{2}(4 \mu \mathrm{l}), 50 \mathrm{pM}$ Primer $(1$ $\mu 1)$ and PCR water $(32.4 \mu \mathrm{l})$ each of it in a Bio-rad Thermal Cycler for 40 cycles, each for $1 \mathrm{~min}$ at $94^{\circ} \mathrm{C}, 1 \mathrm{~min}$ at $35^{\circ} \mathrm{C}$ and $2 \mathrm{~min}$ at $72^{\circ} \mathrm{C}$ and the final extension for $5 \mathrm{~min}$ at $72^{\circ} \mathrm{C}$.

\subsection{Statistical Analysis}

In order to access overall distribution of genetic diversity data was analyzed using Minitab software.

\subsection{Biochemical Characterization}

For biochemical characterization Czapek Dox media (20 g agar, $20 \mathrm{~g}$ sucrose, $0.01 \mathrm{~g} \mathrm{FeSO}_{4}, 0.50 \mathrm{~g} \mathrm{KCl}, 0.50 \mathrm{~g} \mathrm{Mg} \mathrm{SO}_{4}$, $01 \mathrm{~g} \mathrm{~K}_{2} \mathrm{HPO}_{4}$ and $3 \mathrm{~g} \mathrm{NaNO}_{3}$ ) supplementd with $2 \%$ pectin for $A$. niger, $A$. japonicus and $A$. parasiticus, glucose for $A$. nidulans, starch for $A$. flavus and $A$. oryzae are added with starch to observe activity of $\alpha$-amylase specifically and cellobiose for A. fumigatus respective substrate was inoculated with $5.10^{6}$ spores $/ \mathrm{ml}$ and incubated at $30^{\circ} \mathrm{C}$ for $24 \mathrm{~h}$. Plates were stained with Ruthenium red $(0.05 \%)$ solution for 1 hour or with Congo red dye. Destaining was done by $1 \mathrm{M} \mathrm{NaCl}$ and tap water. Plates were observed for their biochemical and enzymatic reaction as by the formation of coloured zone in each case.

\section{Results and Discussion}

Figures 1 and 2 shows polymorphism among seven $A s-$ pergillus species, which means a particular primer, gives different bands to evaluate species with minor genetic differences. A total of 46 bands with primer GL-Decamer B-09 (Figure. 1)

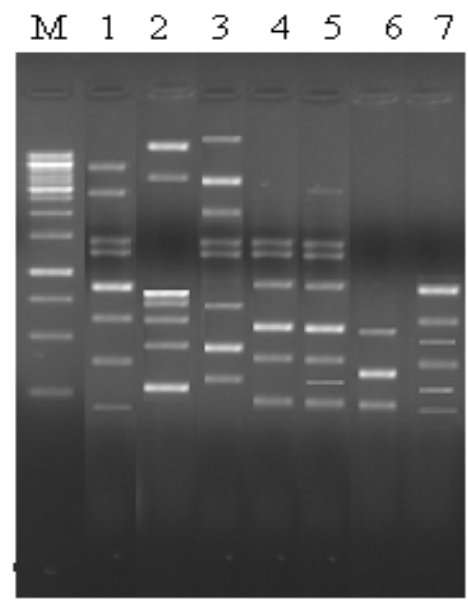

Figure 1. RAPD analysis of Aspergillus specie by primers GL-Decamer B-09. M, 1 kb Ladder; Lane 1, A. niger; lane 2, A. nidulans; lane 3, A. parasiticus; lane 4, A. japonicus; lane 5, A. fumigatus lane 6 , A. oryzae and lane 7 , A. flavus

Total 38 bands with primer GL decamer B-10 (Figure. 2) have been identified.

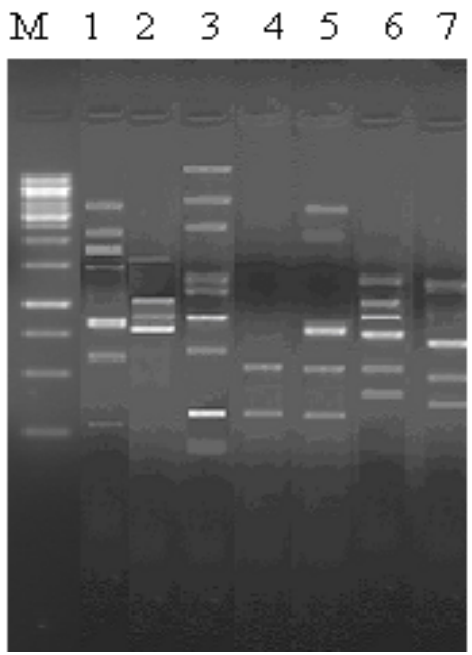

Figure 2. RAPD analysis of Aspergillus specie by primers GL-Decamer B-10. M, 1 kb Ladder; Lane 1, A. niger; lane 2, A. nidulans; lane 3, A. parasiticus; lane 4, A. japonicus; lane 5, A. fumigatus lane $6, A$. oryzae and lane 7, A. flavus

Dandrogram of primer GL Decamer B-09 (Figure. 3) shows that $A$. oryzae and $A$. flavus are $83 \%$ similar to each other. A. parasiticus and A. fumigatus are $80 \%$ similar. $A$. 
niger is $82 \%$ similar to A. parasiticus and A. fumigatus. These two groups are $75 \%$ similar to each other. $A$. nidulans shows $60 \%$ similarity to $A$. oryzae, A. flavus, A. parasiticus, A. fumigtaus and $A$. niger. A. japonicus is $50 \%$ similar to all Aspergillus strains. This result of similarity corresponds to the work of Carbone[16] with respect to $A$. parasiticus.

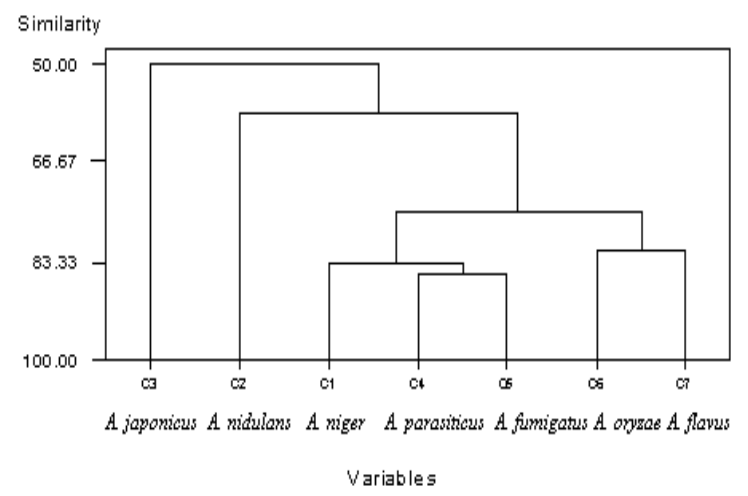

Figure 3. Dandrogram showing genetic diversity with primer GL- Decamer B-09. C1, A. niger, C2, A. nidulans, C3, A. japonicus, C4, A. parasiticus, C5, A. fumigatus, C6, A. oryzae, C7, A. flavus

The dandrogram at figure. 4 shows that $A$. parasiticus and A. fumigatus are $80 \%$ similar to each other. A. oryzae and $A$. flavus $87 \%$ similarity while $A$. japonicus is $68 \%$ similar to $A$. oryzae and A. flavus. A. niger is $55 \%$ similar to the above three species[17].

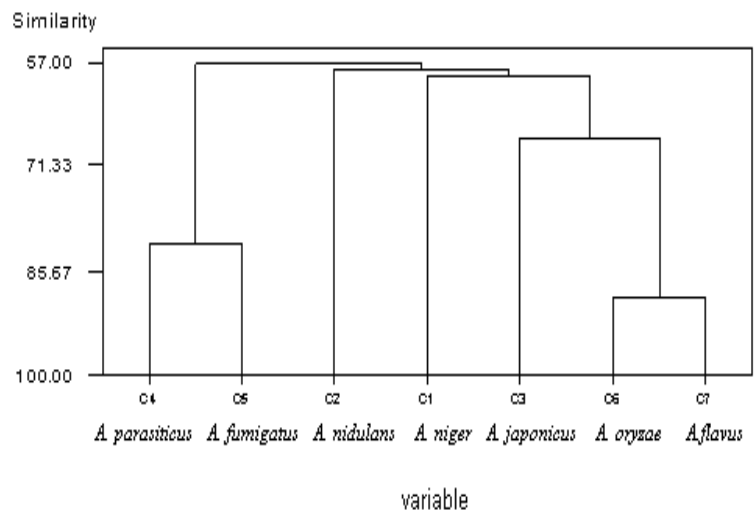

Figure 4. Dandrogram showing genetic diversity with primer GL-- Decamer B-10. C1, A. niger, C2, A. nidulans, C3, A. japonicus, C4, A. parasiticus, C5, A. fumigatus, C6, A. oryzae, C7, A. flavus

$A$. nidulans is $56 \%$ similar with the four species and $A$. parasiticus and A. fumigatus is $57 \%$ similar with all other Aspergillus strains. This data of current research work correlated the result of Pan[18] who analyzed $A$. oryzae, A. flavus and $A$. sojae as control by RAPD technology.

Biochemical characterization elucidated that specific enzyme secreted by particular specie which degrades its respective substrate. This was also mentioned by Carpita[19] that $A$. niger produces pectinase as major enzyme to degrade pectin though there are many other as glucose oxidase, lipase, xylanase, also secreted but the prominent one is pectinase[20]. A. niger, A. japonicus and A. parasiticus was provided with pectin as sole source of carbon substrate and was stained with Ruthenium red dye solution $(0.05 \%)$ for one hour. After one hour tap water destaining light pink demarcation at the zones showed that pectinase enzyme was secreted by these species which hydrolyzed the respective substrate source where growth had been occurred (Table 1).

Table 1. Enzyme activity of different Aspargillus species in response to particular substrate

\begin{tabular}{|c|c|c|c|}
\hline Sr. no. & Species & Substrates & Enzyme Activity (+ve ) \\
\hline 1 & A. niger & Pectin & Pectinase +ve \\
\hline 2 & A. japonicus & Pectin & Pectinase +ve \\
\hline 3 & A. parasiticus & Pectin & Pectinase +ve \\
\hline 4 & A. nidulans & Glucose & Glucose oxidase +ve \\
\hline 5 & A. fumigatus & Cellobiose & $\beta$-glucosidase +ve \\
\hline 6 & A. oryzae & Starch & $\alpha$ - amylase +ve \\
\hline 7 & A. flavus & Starch & $\alpha$-amylase +ve \\
\hline
\end{tabular}

$*+$ ve positive

A. nidulans was grown in glucose as a source of carbon substrate. It was stained with Congo red dye solution $(0.1 \%)$ for one hour and destained with $1 \mathrm{M} \mathrm{NaCl}$ for one hour. Finally the light yellow color of the zones appeared that means glucose oxidase enzyme from the specie brought oxidation of glucose, the respective substrate source (Table 1) as mentioned by Luque in 2004[21].

A. fumigatus secretes $\beta$-glucosidase that was analysed by adding cellobiose as substrate.

A. oryzae and A. flavus have been identified to produce $\alpha$ galactosidase and two distinct $\beta$-glucosidases which were analysed by adding starch in growth medium. A. oryzae and A. flavus were grown in starch as a source of carbon substrate, then stained with Congo red dye solution $(0.1 \%)$ for one hour and destained with $1 \mathrm{M} \mathrm{NaCl}$ for one hour further. Finally the light yellow color of the zones appeared that means $\alpha$-amylase enzyme from both species brought hydrolysis of starch contents that was added as carbon source, the respective substrate of $\alpha$ - amylase (Table 1).

Genetic analysis using RAPD is attractive as no prior knowledge of the DNA sequence is available and primers are designed randomly with the sole constraint being GC contents. It permits simultaneous investigation of multiple loci in a single PCR reaction[22]. Like all other techniques, the RAPD-PCR has limitations; the prominent shortcoming of RAPD is its low band repeatability and occurrence of pseudo bands. But it can be improved by applying suitable conditions to remove the impurities in extracted DNA and keeping the amplification conditions stable. It is concluded that the use of DNA marker can increases the efficiency of analyzing genetic diversity among different fungal isolates, as described by Rath[23].

According to our current research work the data generated by this RAPD study is useful in estimating distances between and within same species and might help future programs of management and conservation. Results indicated that genetic differences between species of the same genus maintain genetic diversity within this population. This study may provoke future research in a way that more and more closely related species of not only fungi but also of any other organism can be characterized at their molecular and bio- 
chemical level. The present research work paved a way of finding minor differences of closely resembling specie at genetic level and more and more evaluation are welcoming in this regard.

\section{ACKNOWLEDGMENTS}

We are thankful to Dr. Rukhsana Bajwa for providing us the fungal strains obtained from First Fungal Culture Bank of University of the Punjab Lahore at Institute of Mycology and Plant Pathology (IMPPL).

\section{REFERENCES}

[1] Meredith, B., Rytas, V., John, W.T., 2005, Eumycota: mushrooms, sac fungi, yeast, molds, rusts, smuts, etc., Appl. Environ. Microbiol., 67, 521-527.

[2] Zeng, R., Luo S., Shi, Y., 2004, Allelopathic effects of secalonia acid $\mathrm{F}$ produced by Aspergillus japonicus on Zea mays., Ying.Yong. Sheng.Tai. Xue.Bao., 15, 145-148.

[3] Baker, S.E., 2006, Aspergillus niger genomics: Past, present and into the future., Med. Mycol., 44, 17-21.

[4] Hong, S.B., Shin, H.D., Nong, J., 2008, New taxa of Neosatorya and Aspergillus in Aspergillus section Fumigatic., Antonie. Van. Leeuwen. hoek., 93, 87-98.

[5] Kurtzman, C.P., Robnett, M.J., Wicklow, D.T., 1986, DNA relatedness among wild and domesticated species in the Aspergillus flavus group., Mycologia., 78, 955-959.

[6] Palumbo, J.D., OKeeffe, T.L., Kattan, A., Abbas, H.K., Johnson, B.J., 2010, Inhibition of Aspergillus flavus in Soil by Antagonistic Pseudomonas Strains Reduces the Potential for Airborne Spore Dispersal., Phytopathology., 100, $532-538$.

[7] Megnegneau, B., Debets, F., Hoekstra, R.F., 1993, Genetic variability and relatedness in the complex group of black Aspergilli based on random amplification of polymorphic DNA., Curr. Genet., 23, 323-329.

[8] Wostemeyer, J., and Kreibich, A., 2002, Repetitive DNA elements in fungi (mycota):impact on genomic architecture and evolution., Curr. Genet., 41, 189-198.

[9] Narasimhan, B., and Asoka, M., 2010, Genetic variability of Aspergillus terreus from dried grapes using RAPD-PC., A.B.B., 1, 345-353.

[10] Loudon, K.W., Burnie, J.P., Coke, A.P., Matthews, R.C., 1993, Application of polymerase chain reaction to fingerprinting Aspergillus fumigatus by random amplification of polymorphic DNA., J. clin. Microbiol., 31, 1117-1121.
[11] Aiat, N., 2006, Genetic Variability among Three Species of Aspergillus 2. Random Amplified Polymorphic DNA (RAPD) Markers for Genetic Analysis., J. Appl. Sci. Res., 2, 709-713.

[12] Williams, J.G.K., Hanafey, M.K., Rafalski, J.A., Tingey, S.V., 1990, Genetic analysis using the random amplified polymorphic DNA marker., Methods. Enzymol., 218, 705-740.

[13] Diaz-Guerra, T.M., Mellado, E., Cuenca-Estrella, M., Gaztelurrutia, L., Navarro, J.I.V., Tudela, J.L.R., 2000, Genetic Similarity among One Aspergillus flavus Strain Isolated from a Patient Who Underwent Heart Surgery and Two Environmental Strains Obtained from the Operating Room., J. Clin. Microbiol., 38, 2419-2422.

[14] Monna, L., Miyao, A., Inoue, T., Fukuoka, S., Yamazaki, M., Zhong, H., Sasaki, T., Minobe, Y., 1994, Determination of RAPD Markers in Rice and their Conversion into Sequence Tagged Sites (STSs) and STS-Specific Primers., DNA. Res., $1,139-148$.

[15] Saghai-Maroof, M.A., Soliman, K.M., Jorgensen, R.A., Allard, R.W., 1984, Fungal DNA Isolation., P.N.A.S., 81, 8014-8018

[16] Carbone, I., Jakobek, J.L., Ramirez-prado, J.H., Horn, B.W., 2007, Recombination, balancing selection and adaptive evolution in the aflatoxin gene cluster of Aspergillus parasiticus., Mol. Ecol., 16, 4401-4417.

[17] Parenicova, L., Skouboe, P., Frisvad, J., Samson, R.A., Rossen, L., Visser, J., 2001, Combined Molecular and Biochemical Approach Identifies Aspergillus japonicus and Aspergillus aculeatus as Two Species., Appl. Environ. Microbiol., 67, 521-527.

[18] Pan, L., Wang, B., Guo, Y., 2007, RAPD analysis of Aspergilli and its application in brewing industry. Wei. Sheng. Wu. Xue. Bao., 47, 533-536.

[19] Carpita, N.C., and Gibeaut, D.M., 1993, Structural models of primary cell walls in lowering plants: consistency of molecular structure with the physical properties of the walls during growth., Plant. J., 3, 1-30.

[20] Teixeira, M.F.S., Filho, J.L., Duran, N., 2000., Carbon Sources Effect On pectinase production from Aspergillus Japonicus 586., Braz. J. Microbiol., 31, 286-290.

[21] Luque, R., Orejas, M., Perotti, N.I., Ramon, D., Lucca, M.E., 2004, $\mathrm{pH}$ Control of the production of recombinant glucose oxidase in Aspergillus nidulans., J. Appl. Microbiol., 97, 332-337.

[22] Bhattacharya, E., and Ranade, S.A., 2001, Molecular distinction amongst varieties of Mulberry using RAPD and DAMD profiles., BMC. Plant. Biol., 1, 3.

[23] Rath, P.M., Petermeier, K., Verweij, P.E., Ansorg, R., 2002, Differentiation of Aspergillus ustus Strains by Random Amplification of Polymorphic DNA., J. Clin. Microbiol., 40, 2231-2233. 